\title{
NIVEL DE ESTRESSE PRÉ-COMPETITIVO EM ATLETAS UNIVERSITÁRIAS DO SEXO FEMININO PRATICANTES DO FUTSAL
}

Vinicius Barroso Hirota

Veronica Amorim Tragueta

Carlos Eduardo Lopes Verardi

\section{Resumo}

O futsal feminino apresenta-se bastante difundido na pratica universitária, e um dos principais aspectos psicológicos apresentados durante o jogo é o estresse. Com o objetivo de identificar o estresse précompetitivo em atletas universitárias que atuam no futsal feminino (n: 32, de idade entre 18 e 26 anos), este estudo é uma pesquisa descritiva (CERVO e BERVIAN, 2004), que conta com a aplicação da escala LSSPCI - Lista de Sintomas de Estresse Pré - Competitivo (DE ROSE JR., 1998). Para o tratamento estatístico utilizamos o calculo do Coeficiente Alfa de Cronbach a fim de avaliar a consistência e validade da escala, e a média, identificando o nível de estresse. Os resultados nos mostraram Alfa de 0.91 e a média das atletas focou em 2,59. Assim aferimos a validade da escala como uma estabilidade no nível de estresse das atletas.

\section{Palavras-Chave}

Avaliação; Estresse; Futsal feminino.

\section{LEVEL OF STRESS PRE-COMPETITIVE IN PRACTICING UNIVERSITY ATHLETES OF THE FEMININE SEX OF THE FUTSAL}

Vinicius Barroso Hirota

Veronica Amorim Tragueta

Carlos Eduardo Lopes Verardi

\begin{abstract}
The female futsal comes quite spread in the academical practices, and one of the main psychological aspects presented during the game is the stress. With the objective of identifying the pré-competitive stress in academical athletes that act in the female futsal (n: 32, of age between 18 and 26 years), this study is a descriptive research (CERVO and BERVIAN, 2004), that counts with the application of the scale LSSPCI - List of Symptoms of Estresse Pré - Competitive (DE ROSE JR., 1998). For the statistical treatment we used calculations of the Coeficiente Alfa of Cronbach in order to evaluate the consistence and validity of the scale, and the average, identifying the stress level. The results showed us Alpha of 0.91 and the athletes' average focused in 2,59 . We checked like this the validity of the scale as a stability in the level of the athletes' stress.
\end{abstract}

\section{Key-Words}

Evaluation; Stress; Female futsal. 


\section{INTRODUÇÃO}

O futsal brasileiro e um esporte que conquistou seu espaço no meio esportivo mundial. A idéia de que nosso pais intitulasse de Pais do Futebol, possibilitou a revelação de diversos talentos esportivos, e nos atribuiu o quinto titulo mundial na modalidade. E de nosso conhecimento também, que o espaço destinado a mulher dentro do futsal ainda e restrito, mas as mesmas tem a idéia de conquista pelo espaço, assim como no futebol de campo, onde conquistamos o Pan Americano e o Vice Campeonato Mundial.

Figueiredo (2000) ao analisar as variáveis que interferem no desempenho do atleta, destaca; a motivação como um "forca" que impulsiona as pessoas a determinadas ações, porem, ela e observada, no ambiente no qual o atleta esta inserido. $\mathrm{O}$ ambiente competitivo apresenta inúmeros fatores estressantes para o atleta, sendo que algumas estratégias podem auxiliar o atleta a lidar com o excesso de ansiedade e tensão. Sendo assim, na pratica esportiva existem diversos fatores que contribuem, e/ou dificultam o desempenho das atletas. Dentre estes fatores, podemos destacar a motivação, a ansiedade, e o estresse pre-competitivo, este último, o objetivo deste estudo.

\section{ESTRESSE E DESEMPENHO ESPORTIVO}

Segundo Weineck (2003) a capacidade de desempenho esportivo e na sua composição multifatorial, sendo assim, proporciona dificuldades no planejamento do treinamento esportivo. Somente o desenvolvimento harmônico de todos os fatores determinantes do desempenho esportivo, possibilitara a obtenção do alto desempenho individual. Desta maneira entendemos que os aspectos motores, sociais, afetivos, cognitivos, físicos e psicológicos devem ser desenvolvidos em equilíbrio, possibilitando que a atleta possa desempenhar o seu ótimo durante uma partida de futsal, em busca da auto-superação. Mas como conviver com o fator de estresse que antecede e perdura durante as competições?

$\mathrm{O}$ estresse e um conceito indefinido, pois, na maioria das vezes, usa- se a palavra estresse para descrever ameaças ou desafios. Outras vezes para descrever nossas reações, porem, estresse não e apenas um estimulo ou uma resposta, mais sim o processo pelo qual avaliamos e lidamos com as situações e desafios do ambiente. A reação adaptativa do corpo ao estresse possui três fases: na primeira se experimenta uma reação de alarme pela ativação do sistema nervoso simpático; na segunda fase, a resistência do corpo esta pronta para combater o desafio. Persistindo o estresse as reservas do corpo se esgotam e causam a terceira fase: a exaustão (MYERS, 1999). 
Machado (1997) relata que o estresse, se manifesta como uma sindrome especifica, composta por todas as variações não especificas, provocadas dentro de um sistema biológico. Afirma ainda que existe uma concepção de que estresse que e primeiramente um fenômeno negativo, esta sempre relacionado com perigos ou prejuízos. Entretanto o estresse e necessário a vida para a manutenção e aperfeiçoamento das capacidades funcionais, como a auto - proteção e conhecimento dos seus próprios limites.

O desempenho esportivo depende da forma em que o atleta interpreta os estressores, esta influenciara o seu desempenho; "a resposta ao estressor pode ser tanto negativa quanta positiva, dependendo da percepção de ameaça, da preocupação e do medo ou de uma reação positiva e desafiadora, desejável ao processo de competição" (BRANDÃO, 2002).

Segundo Samulski (2002) a concepção de estresse e compartilhada e discutida entre diferentes autores, e refere-se a desestabilização psicofísica ou perturbação do equilíbrio entre pessoa e meio ambiente. De Rose Jr. (2002) descreve que como qualquer atividade do ser humano, o esporte também pode ser um potencial gerador de estresse, se não for adequado as necessidades e potencialidades do praticante, principalmente se esse for despreparado e não estiver pronto para enfrentar situações complicadas inerente ao processo competitivo.

Em conjunto com a descrição de diversos autores podemos levar em consideração alguns aspectos importantes onde podemos chamar de extrinsecos, ou seja, a relação que o individuo vai estabelecer com o meio ambiente, durante a pratica esportiva. A torcida, os pais, o técnico, a temperatura ambiente e a complexidade da tarefa a ser realizada poderá aumentar ou diminuir o nível de estresse, como o time adversário a ser enfrentado. $\mathrm{O}$ desafio e um fator determinante para o atleta.

Portanto experiências anteriores que o atleta tenha vivenciado poderão controlar o nível de estresse que antecede a competição.

De Rose Jr. (2002, p. 73) diz que no contexto esportivo, o estresse pode ser identificado a partir de algumas causas:

- Complexidade da tarefa maior que os recursos do praticante;

- Pressão exercida por adultos envolvidos no processo competitivo: pais e técnicos; 
- Definição irreal de objetivos;

- Comportamento dos adultos nas competições;

- Nível de expectativa exagerado (pessoal e dos outros) em relação ao desempenho;

- Treinamento e especialização precoces.

Weinberg e Gould (2001) descrevem o estresse como um processo que contem quatro estagios. Primeiramente, e colocado ao individuo uma demanda que pode ser física ou psicológica, depois no segundo estagio ocorre a percepção referente a demanda, que e diferente para cada individuo, apos ocorre a resposta conforme a demanda apresentada e o ultimo estagio e o comportamento do individuo mediante ao estresse provocado, esse processo e um ciclo continuo principalmente quando a resposta e negativa.

Samulski (2002) ao referir-se sobre as emoções na fase pré-competitiva descreve que, nos momentos que antecedem a competição, o atleta se encontra em um estado de intensa carga psíquica (estresse psíquico). Este estado caracteriza-se, pela antecipação da competição, e consequentemente antecipa as oportunidades, riscos e conseqüências. Esta fase denominada de estado pré-competitivo, frequentemente e acompanhada, de medo, e temor.

Em relação ao esporte, Becker Jr. (2000) esclarece, o estresse age de forma diferenciada em cada atleta, indicando que as pesquisas sugerem que o estresse e apresentado em maior nível em atletas jovens, do sexo feminino e com pouca experiência.

\section{OBJETIVO}

Este estudo tem como objetivo identificar o estresse pré-competitivo em jogadoras universitárias de futsal do sexo feminino.

\section{METODOLOGIA}

\section{MODALIDADE DA PESQUISA}

Com o objetivo de identificar o estresse pré-competitivo em atletas universitárias que atuam no futsal feminino, este estudo apresenta características da pesquisa descritiva, já que ela observa, analisa e correlaciona fatos ou fenômenos (variáveis) sem manipula-los (CERVO; BERVIAN, 2004). 


\section{INSTRUMENTO}

O instrumento utilizado para a coleta dos dados foi a escala LSSPCI - Lista de Sintomas de Estresse Pré - Competitivo (De Rose Jr., 1998), do tipo Likert, que foi desenvolvida para identificar nível de estresse que antecede as competições.

\section{AMOSTRA}

A amostra foi constituída por 31 jogadoras de futsal, do sexo feminino, nível universitário, entre 18 a 26 anos de idade, devidamente matriculadas em universidades de São Paulo.

\section{PROCEDIMENTO PARA COLETA DE DADOS}

Para atender os objetivos do estudo, inicialmente foi estabelecido um Termo de Consentimento Livre e Esclarecido, na qual as atletas para estar de acordo em participar do estudo, as condições foram a devolução deste termo devidamente assinado. O segundo passo a ser levado em consideração era que as atletas respondessem ao questionário individualmente, para que não houvesse interferência nos resultados. Para que não houvesse problema durante a coleta dos dados foram fornecidas a cada atleta, caneta, prancheta e uma folha contendo a copia da escala LSSPCI.

\section{TRATAMENTO ESTATÍSTICO}

Para o tratamento estatístico utilizamos o calculo do Coeficiente Alfa de Cronbach com o emprego do software SPSS - DATA EDITOR, versão 13.0 for Windows a fim de avaliar a consistência interna dos itens da escala. Outro calculo apresentado foi a contagem da media da escala, identificando o nível do estresse pré-competitivo.

\section{RESULTADOS E DISCUSSÃO}

Feita a coleta dos dados e a tabulação dos mesmos, o próximo passo deste estudo foi a sua analise. $\mathrm{O}$ primeiro item a ser analisado foi o coeficiente Alfa de Cronbach que demonstra a validade e fidedignidade do instrumento. Nas atletas de futsal universitário obtivemos um resultado de Alfa de 0.91. Comparando com outros estudos realizados, o resultado obtido e extremamente relevante.

Durante o processo de validação da escala em questão De Rose Jr. (1998) obteve resultado de coeficiente Alfa de 0.97, aplicado em 219 atletas, entre 10 e 14 anos de idade, de ambos os sexos. 
De Rose Jr. et al (2000), avaliou 723 jovens (363 meninos e 360 meninas) de 10 a 17 anos, e teve como resultado de Coeficiente Alfa de 0.95. Em estudo mais recente realizado por Hirota e Verardi (2006), com uma equipe de futsal, composta por 13 atletas, todos do sexo masculino, de idade compreendida dos 18 anos 23 anos, participantes de campeonatos regionais inter faculdades do grande $\mathrm{ABC}$, o resultado de Alfa foi de 0.90. Hirota e De Marco (2006) em um estudo com 318 jovens atletas, de futebol de campo, entre 10 e 17 anos de idade, mostrou resultado de Alfa de 0.92.

Sendo assim podemos aferir que a escala proposta por De Rose Jr. Em 1998, apresenta uma ótima consistência interna dos itens, mostrando fidedignidade e validade ao instrumento mesmo com atletas que superam os 14 anos, uma vez que a escala foi validada para idade entre 10 e 14 anos.

Outro aspecto a ser levado em consideração e a media resultante da escala, onde obtivemos o valor de 2,59 entre as 32 atletas.

Palhano et al (1996), utilizaram a LSSCPI para comparação entre grupos divididos por faixa etária e sexo. Nesse estudo foram analisados 301 atletas, 152 meninos e 149 meninas, subdivididos em 3 faixas etárias diferentes $(\mathrm{A}=$ ate 12 anos, $\mathrm{B}=$ ate 14 anos e $\mathrm{C}=$ ate 16 anos). Os resultados obtidos pela pesquisa, gerou as seguintes medias: para o grupo masculino $\mathrm{A}=2.60, \mathrm{~B}=2.51, \mathrm{e} \mathrm{C}=2.68$; e para o grupo feminino $\mathrm{A}=2.88, \mathrm{~B}=2.80$, e $\mathrm{C}=2.87$. Foram comparados os resultados e não houve diferenças estatisticamente significantes entre as faixas etárias do mesmo sexo. Concluindo-se que, a faixa etária não influencia, quando essa esta sendo comparada com atletas do mesmo sexo. Todos apresentaram uma freqüência considerada moderada e foi notado em relação ao sexo feminino que esse apresentou níveis de stress significantemente maiores que do sexo masculino.

Assim como no estudo de Palhano et al. (1996), Hirota e Verardi (2006) ao analisar atletas do sexo masculino, praticantes do futsal universitário, obtiveram media de 2,48. Valor este, pouco abaixo quando comparados ao sexo feminino, não reafirmando os resultados encontrados no estudo de Palhano et. al (1996).

Hirota e De Marco (2006) ao pesquisar futebolistas de 10 a 17 anos de idade, do sexo masculino, apresentou media de 2,47, evidenciou-se que, em relação a faixa etária, existe pouca diferença. Portanto de acordo com Becker Jr. (2000), as atletas do sexo feminino, tem maior preponderância a serem mais estressadas ante as competições. 
Korsakas; De Rose Jr. (1998), com objetivo de comparar a ocorrência dos sintomas de estresse, entre atletas escolares e atletas de clube, avaliou 172 atletas. Sendo 76 escolares $($ masculino $=46$, feminino $=$ 30) e 94 atletas e clube (masculino $=42$, feminino $=52$ ), praticantes das modalidades voleibol e basquetebol, com idades entre 12 a 17 anos.Na escola os meninos obtiveram media de 2,56, enquanto as meninas apresentaram um valor mais elevado demonstrando-se mais estressadas ficando em 2,86. No clube, a media dos meninos ficou em 2,59 e das meninas 2,75, reafirmando um valor mais elevado em meninas.

Pinto et al (1999), desenvolveram um estudo entre 52 jogadores de futebol das categorias juvenil e juniores de 14 a 18 anos de idade, sendo 4 goleiros, 17 defensores, 18 meio campistas e 13 atacantes, com o objetivo de identificar os sintomas de estresse pré- competitivo, e comparar a ocorrência de acordo com as posições especificas do jogo. Neste estudo foi obtida uma media geral de freqüência de ocorrência de 2.51. Ao avaliar as posições de jogo, os goleiros apresentaram a media mais baixa 2.33, e os atacantes as médias mais altas 2.6. Porem concluiu-se que não houve diferenças significativas entre os grupos dos jogadores, considerando que a media e moderada e semelhante a estudos entre jogadores de outros esportes coletivos.

Nos estudos De Rose Jr. et al (2000), com 723 jovens (363 meninos e 360 meninas) de 10 a 17 anos de idade, os resultados obtidos revelam que as meninas apresentam uma freqüência de ocorrência de estresse significativamente maior, quando comparadas aos meninos. Os sintomas mais freqüência foram, emocionais e cognitivos. Apesar dessa diferença, existe uma semelhança na percepção dos sintomas.

Em nosso estudo ao analisar as medias obtidas com cada questão, verificamos que algumas delas tem baixos resultados:

- Questão de numero 08: Roo (como) as unhas? Media de 1,75;

- Questão de numero 17: Minha boca fica seca? Media de 1,96;

- Questão de numero 19: A presença de meus pais na competição me preocupa? Media de 1,5.

A menor media obtida foi justamente na questão de numero 19, onde estabelece uma relação com a presença dos pais. A amostra aqui estudada tem idade entre 18 e 26 anos. Nesta idade observa-se que poucos pais tem o habito de acompanhar os jogos de seus filhos. 
Em relação as medias mais elevadas estão relacionadas as questões a seguir:

- Questão de numero 01: Meu coração bate mais rápido que o normal? Media de 2,87;

- Questão de numero 03: Fico agitado(a)? Media de 2,93;

- Questão de numero 11: Tenho medo de competir mau? Media de 2,81;

- Questão de numero 16: Fico preocupado(a) com o resultado da competição? Média de 3,03;

- Questão de número 18: Sinto muito cansaço ao final do treino? Média de 2,75;

- Questão de número 26: Fico ansioso(a)? Media de 3,28;

- Questão de número 28: Tenho medo de decepcionar as pessoas? Media de 2,75;

- Questão de número 29: Sinto - me mais responsável? Média de 3,21;

- Questão de número 30: Sinto que as pessoas exigem muito de mim? Media de 2,84;

- Questão de número 31: Tenho medo de cometer erros na competição? Media de 3,25.

A questão com media mais elevada e de número 31, onde a atleta tem medo de cometer erros durante a competição. Seguida da questão 29, onde a atleta sente-se mais responsável antecedendo ao jogo, e que provavelmente esta responsabilidade seja levada ate durante o jogo.

Verificamos também que as questões com medias mais elevadas tem relações com aspectos extrínsecos (fatores externos), outras pessoas e mesmo relacionados ao ambiente, onde ficar preocupado com o resultado da competição e sentir que as pessoas exigem muito de mim, refletem nestes aspectos.

Alem disso, aspectos físiológicos apresentam-se alterados pela percepção individual de cada atleta, como medo de cometer erros e medo de decepcionar as pessoas, ficar mais ansioso, preocupado e cansaço apos o treino. (achei confuso este parágrafo).

\section{CONSIDERAÇÕES FINAIS}

Com base em nosso estudo consideramos que, a escala proposta, encontra-se fidedigna e com uma excelente confiabilidade a modalidade esportiva escolhida, o futsal; e ao universo feminino, onde poucos estudo ainda foram realizados.

E oportuno destacar que, o estresse pre-competitivo, pode causar alterações consistentes no comportamento de uma atleta antes da competição, desfigurando suas horas de sono, e durante a pratica esportiva, prejudicar seu desempenho. 
Com base nos resultados obtidos com a escala de estresse, podemos inferir que, as atletas apresentam-se com alterações significativas em seus comportamentos, antecedendo as competições.

\section{REFERÊNCIAS}

BRANDÃO M. R. F. O lado mental do futebol. In: BARROS T. L., GUERRA, I. (Orgs.). Ciência do futebol. Barueri: Manole, 2004

BECKER JR. B. Manual de psicologia do esporte \& exercício. Porto Alegre: Nova Prova, 2000. CERVO, A. L.; BERVIAN, P. A. Metodologia cientifica. 5. ed. São Paulo: Prentice Hall, 2004.

DE ROSE JR., D. Lista de sintomas de "stress" pré competitivo infanto juvenil: elaboração e validação de um instrumento. Revista Paulista de Educação Física e Esportes, v. 12, n. 2, p.126-133, 1998.

DE ROSE JR. D. et al. Sintomas de estres precompetitivo en jovens deportistas Brasileiros. Revista de Psicologia del Deporte-RPD, v. 9, n.1/2, p. 143-157, 2000.

DE ROSE JR., D. Esporte e atividade fisica na infância $e$ adolescência: uma abordagem multidisciplinar. São Paulo: Artmed, 2002.

FIGUEIREDO, S. H. Variáveis que interferem no desempenho do atleta de alto rendimento. In: RUBIO, K. (Org.). Psicologia do esporte: interfaces, pesquisa e intervenção. São Paulo: Casa do Psicólogo, 2000. p. 113-124.

HIROTA, V. B.; VERARDI, C. E. L.. Identificação do nível de estresse pré -competitivo em equipe de Futebol de salão universitário do sexo masculino. Revista Brasileira de Educação Física e Esporte. São Paulo, v. 20. p. 415-415, 2006.

HIROTA, V.B.; DE MARCO, A. Motivação para aprendizagem esportiva no futebol de campo: um estudo com o questionário de orientação para orientação para tarefa ou ego (TEOSQ). 2006. Dissertação ( Mestrado) - Facis, Universidade Metodista de Piracicaba, Piracicaba, 2006.

KORSAKAS, P.; DE ROSE JR. D. Stress e esporte infantil: comparação entre atletas escolares e atletas de clube. V CICEEFE-III SPGEEFE - Escola de Educação Física e Esporte -USP.P.97.1998.

MACHADO.A. A Psicologia do esporte: temas emergentes. 9. ed. Jundiai: Apice, 1997.

MYERS, D. Introdução a psicologia geral. 4. ed. Rio de Janeiro: Livros Técnicos e Científicos, 1999.

PALHANO, C. et al. Comparação da freqüência de ocorrência dos sintomas de stress pré-competitivo em atletas infanto-juvenis. Instituto de Psicologia da USP/GEPPE-EEFUSP.p.49.1996

PINTO M. A. V. et al. Sintomas de stress pré-competitivo no futebol. In: SIMPÓSIO INTERNACIONAL DE CIÊNCIAS DO ESPORTE - ATIVIDADE FÍSICA, DA COMUNIDADE AO ALTO RENDIMENTO, 22. CELAFISCS.P.89.1999. 
SAMULSKI, D. M. Psicologia do esporte. São Paulo. Manole. 2002.

WEINBERG, R. S.; GOULD, D. Fundamentos da psicologia do Esporte e do exercicio. 2. ed. Porto Alegre: Artmed, 2001.

WEINECK, J. Treinamento ideal. Barueri: Manole, 2003. 


\section{Vinicius Barroso Hirota}

Universidade Presbiteriana Mackenzie

\section{Veronica Amorim Tragueta}

Universidade Presbiteriana Mackenzie

\section{Carlos Eduardo Lopes Verardi}

\section{Centro Universitário de Votuporanga -UNIFEV}

\section{Referência do artigo:}

ABNT

HIROTA, V. B. et al. Nível de estresse pré-competitivo em atletas universitárias do sexo feminino praticantes do futsal. Conexões, v. 6, p. 487-497, 2008.

\section{APA}

Hirota, V. B., Tragueta, V. A., \& Verardi, C. E. L. (2008) Nível de estresse pré-competitivo em atletas universitárias do sexo feminino praticantes do futsal. Conexões, 6, 487-497.

\section{VANCOUVER}

Hirota VB, Tragueta VA, Verardi CEL. Nível de estresse pré-competitivo em atletas universitárias do sexo feminino praticantes do futsal. Conexões, 2008; 6: 487-497. 